means, the radiographic examination has shown that the foetal head was also small, and that while there was undoubted pelvic contraction there was no true disproportion. Indeed, it is quite surprising how often this is so: the small woman very often has the small baby. Occasionally, however, the charts reveal grave difficulty of which no adequate warning is given by clinical examination. In these cases I have hitherto usually adopted the policy of allowing a " trial of labour," for I have realized that the radiographic method has still to prove its worth. But this I can say with full assurance : the charts quickly " separate the sheep from the goats" (I trust this expression will not cause offence !), and show at once which patients are suitable for domiciliary delivery and which should be referred to hospital for careful supervision.

It is difficult to give statistics regarding the accuracy of the obstetric forecast, for there is, in practice, no uniformly applicable yardstick by which this can be judged. How is one to define, for example, what is meant by a difficult labour and what is meant by an easy labour? How is one to class the case in which there has been a long and obviously difficult labour but no evidence of cephalo-pelvic disproportion - for example, the primigravida with primary inertia followed, maybe, by a contraction ring ? Again, what is one to say about the case in which an overenthusiastic house-surgeon has applied forceps for indications that would generally be deemed inadequate? These and other difficulties in assessing results become obvious when statistics are being compiled; and no system of prognosis, however good in itself, can therefore give a forecast that approaches $100 \%$ accuracy. Nevertheless, having regard to these limitations, a strict analysis of 193 assessable cases of clinically suspect pelvic abnormality was attempted and gave the following results.

When easy delivery was indicated by the graphs the labour in $72 \%$ of cases was found to be short, spontaneous, and uneventful. This figure would be higher if borderline cases were included or allowance made for the "substantially correct" diagnosis as defined by Rohan Williams.

When difficult delivery was indicated by the graphs the labour in $86 \%$ of cases was found to be prolonged or to require operative assistance. When dystocia was indicated by contraction in the brim graph, as distinct from the cavity and outlet graphs, the accuracy was even higher.

These results were on an early series; with further experience a higher rate of correct forecast seems possible, and this, I hope, will be the subject of a future report.

\section{Intra-partum Radiography}

And now a brief note on intra-partum radiography. It is quite remarkable how little attention has hitherto been paid to this obvious use of the radiograph. By it the progress of labour can be observed, and much help given, for examp'e, in the conduct of the "trial-labour" case. It will show whether the greatest diameter of the head has passed or has nearly passed through the narrowest part of the pelvis, and hence whether or not it is reasonable to subject the mother and the baby to further hours of "trial labour." One can only suppose that lack of radiographic facilities has been the reason for this failure to utilize a modern diagnostic method, and it seems to me that an obstetric hospital without radiographic faci'ities for the parturient woman is as much an anachronism as, say, a cardiological hospital without an electrocardiograph.

\section{Conclusion}

Finally, a word of warning. Let no one suppose that radiography provides a short cut to good obstetrics. The clinical problems involved are sufficiently numerous and varied to make any such supposition quite untenable. But, on the other hand, he is a bold man who would brush aside the help that radiography can give. To ignore its aid and to trust exclusively to clinical judgment in sizing up the problems presented in a border-line case of disproportion is, to my mind, a policy reminiscent of the alleged behaviour of the ostrich on the approach of danger.

REFERENCES

Ball, R. P. (1936). Surg. Gynec. Obstet., 62, 798 and Marchbanks, S. S. (1935). Radiology, 24, 77. Caldwell, W. E., Moloy, H. C., and Swenson, P. C. (1939). Amer. J. Roentgenol., 41, 305, 505, 719 .

Kenny, M. (1944). J. Obstet. Gynaec. Brit. Emp., 51, 277.

Moir, J. C. (1941). Edinb. med. J., 48, 361 .

(1946). J. Obstet. Gynaec. Brit. Emp., 53, 487

(1947). Ibid., 54, 20.

Nicholson C. (1938) Ibid., 45, 950.

Nicholson, (1943). Ibid., 50, 37.

Thoms, H. (1933). Radiology, 21, 125.

Williams, E. R. (1943). Brit. J. Radiol., n.s. 16, 173

and Phillips, L. G. (1946). J. Obstet. Gynaec. Brit. Emp., 53. 125.

\section{GROWTH OF THE FOETAL BIPARIETAL DIAMETER DURING THE LAST FOUR WEEKS OF PREGNANCY*}

BY

SYDNEY JOSEPHS, M.D., D.M.R.

Assistant Radiologist, Newcastle General Hospital, Newcastle-upon-Tyne

With Statistics by H. Campbell, B.A., F.S.S. Nuffield Department of Industrial Health, University of Durham King's College, Newcastle-upon-Tyne

It has long been accepted that the foetal skull grows at a uniform rate during the last weeks of pregnancy, and this view is supported by the work of Scammon and Calkins (1929). They state that the foetal biparietal diameter increases by approximately 0.1 in. $(2.5 \mathrm{~mm}$.) a week during the last four weeks of pregnancy, and Reece (1935) based his method of estimating the age of the foetus on their growth curve of the biparietal diameter.

Three years ago the departments of radiology and obstetrics at the Newcastle General Hospital decided to try out a new method of cephalometry. In an attempt to check its accuracy by direct measurement of the foetal head after delivery the following course was adopted.

After each cephalo-pelvic estimate a copy of the radiologist's report, with the date of examination, was filed in a card index. A list of all patients examined, containing no other information than the expected dates of delivery, was kept by Dr. Ruth Fawcett, paediatric registrar to the maternity department, who then measured the biparietal diameter of each baby's head on the third day after delivery. This day was chosen because by that time it was considered that the effects of moulding would have disappeared (Chassar Moir, 1946). The measuring was done with a pair of engineer's cal'ipers, and it was Dr. Fawcett's practice to measure each biparietal diameter three times, the mean of these three measurements being

* Read at a combined mee:ing of the Sections of Obstetrics and Gynaecology and Radiology at the Annual Meeting of the British Medical Association, Harrogate. 1949. The paner was bared on a thesis presented for a degree of M.D. at the University of Durham June, 1949, wi.h the addition of fresh cases and material. 


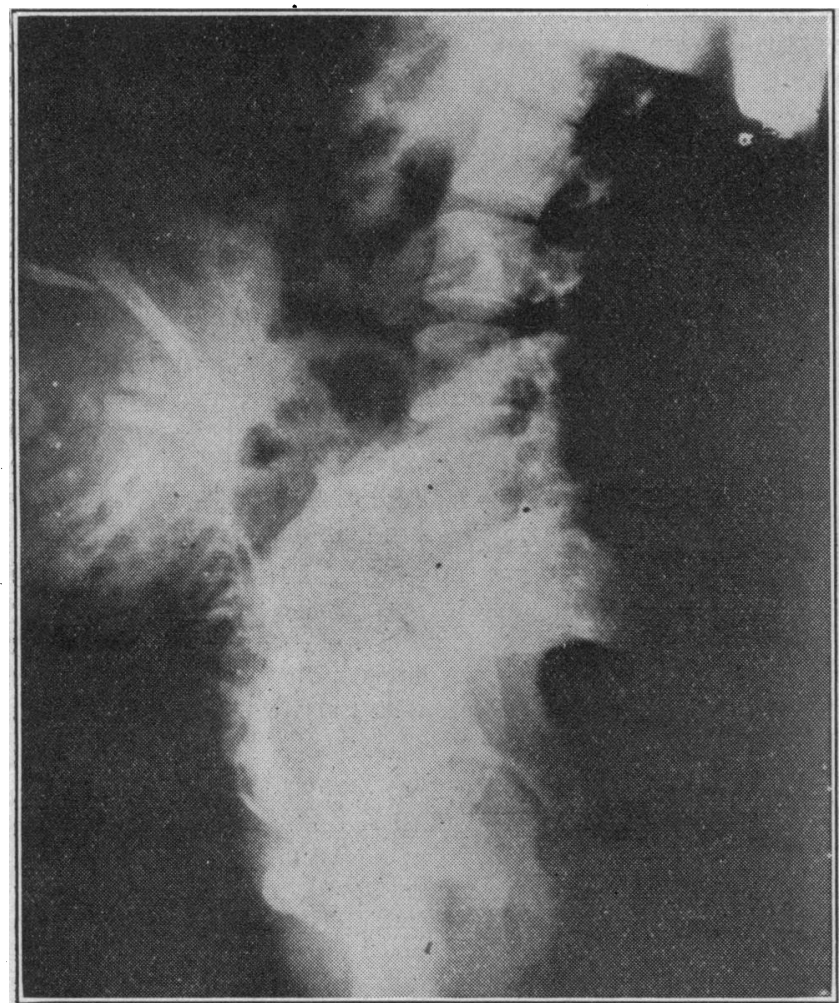

FIG. 1.-Radiograph taken on February 11.

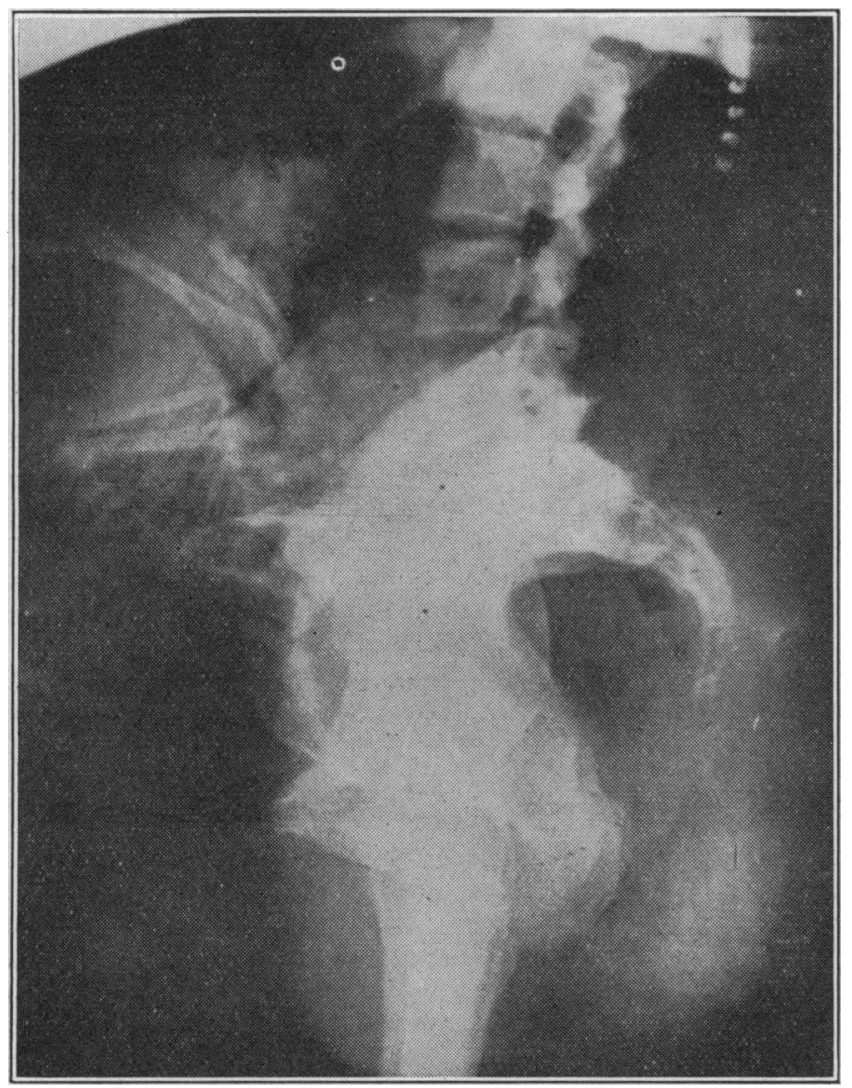

Fig. 2.-Radiograph taken on March 4.

taken as the observed biparietal diameter of the baby's head. These were true! independent observations, unbiased by any knowledge of the radiological estimations.

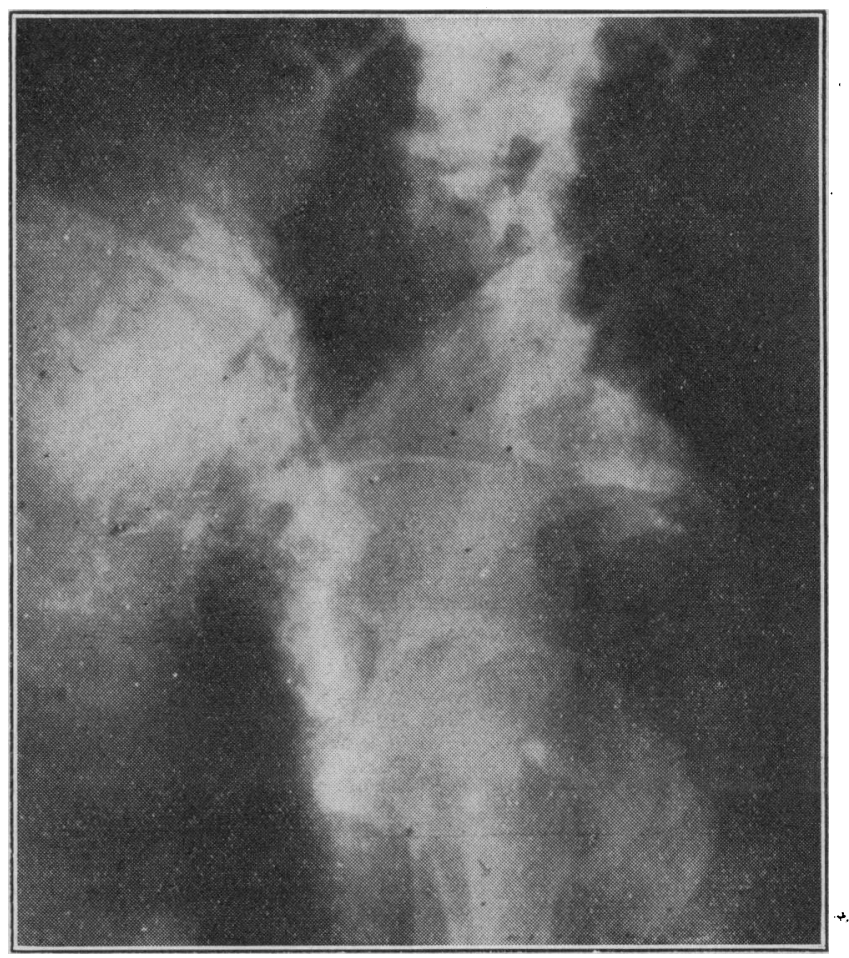

Fig. 3.-The foetal skull shadows in Figs. 1 and 2 are shown superimposed.

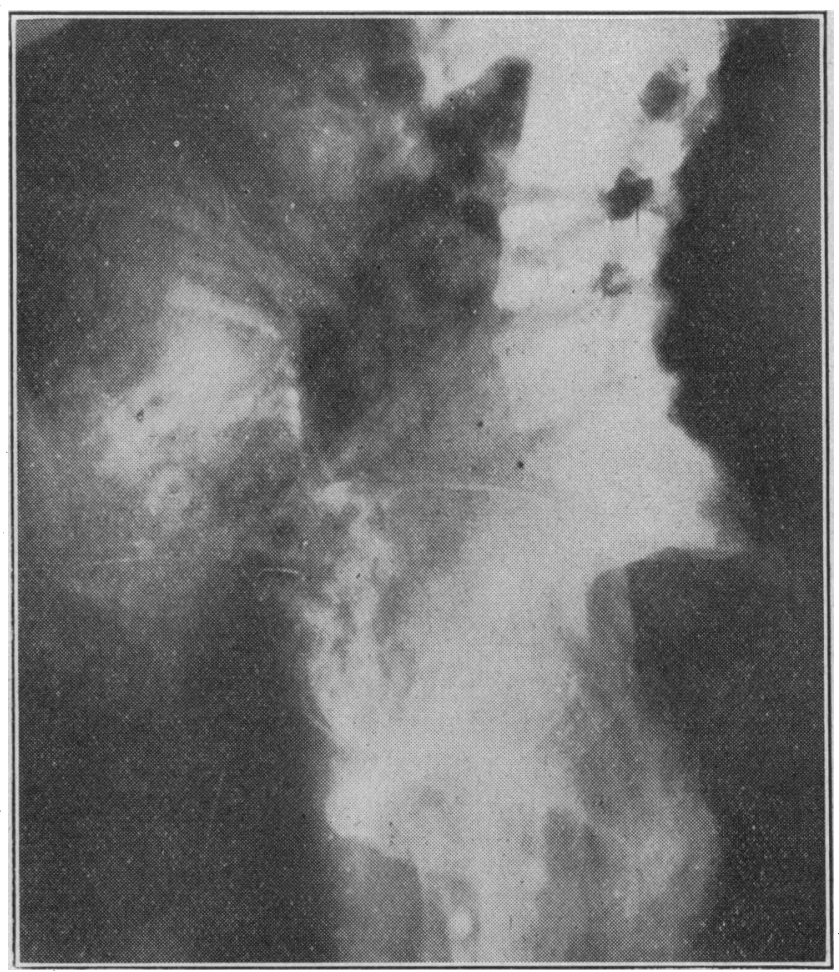

Fig. 4.-The maternal pelves are shown superimposed. The descent made by foetal head in 21 days is seen.

The biparietal diameter was chosen for the following reasons: (1) It, or its equivalent diameter of the greatest circular section of the foetal head, is recognizable in any projection of the foetal skull (Reece, 1935). (2) It is the most certainly defined diameter when measuring the baby's head after birth. (3) In the majority of cephalic 
presentations the biparietal diameter of the foetal head engages with the antero-posterior diameter of the pelvic brim, which is usually the shortest diameter of the inlet.

\section{Results}

In 189 cases the biparietal diameters were estimated radiologically in utero and subsequently measured with callipers after birth ; of these, 34 were examined twice, giving 223 radiological examinations.

Eighty-four cases were examined radiologically seven days or less before delivery, 13 of them actually on the day of delivery, so that the growth that could have occurred between the radiological and calliper measurements was negligible. These 84 cases were used, therefore, to check the accuracy of the method. The two sets of measurements are shown in Table $I$.

\begin{tabular}{|c|c|c|}
\hline $\begin{array}{l}\text { No. of cases } \\
\text { Mean biparietal diameter } \\
\text { Standard deviation } \\
\text { Standard error of } \text { mean .. }\end{array}$ & 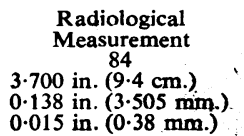 & \begin{tabular}{cc} 
& $\begin{array}{c}\text { Calliper } \\
\text { Measurement }\end{array}$ \\
$\therefore \quad$ & \multicolumn{1}{c}{$\begin{array}{c}84 \\
\therefore \quad\end{array}$} \\
$\therefore \quad$ & 0.680 in. $(9.35 \mathrm{~cm})$. \\
$\therefore \quad$ & 0.014 in. $(3.15 \mathrm{~mm})$.
\end{tabular} \\
\hline
\end{tabular}

It is therefore apparent that the radiological method gives an accurate estimate of the post-natal measurement, with a slight tendency to exaggerate it by $0.02 \mathrm{in}$. $(0.5 \mathrm{~mm}$.). In individual cases, however, there are certain discrepancies which require further consideration. The difference between the intrauterine measurement and the post-natal measurement for these 84 cases is shown in Table II. A negative discrepancy indicates that the intrauterine measurement was larger than the post-natal one.

TABLE II.-Discrepancies in the Radiological Estimation of the Biparietal Diameter of the Foetal Skull

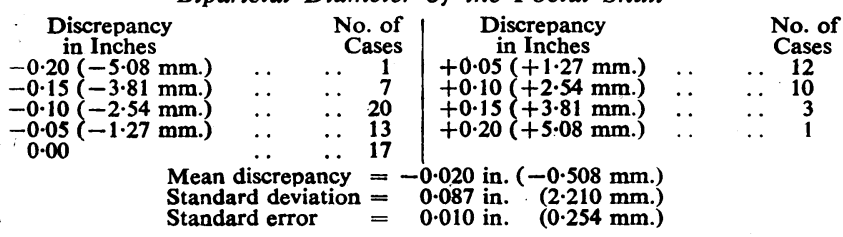

From this table it is apparent that no error occurred greater than 0.2 in., and on the basis of these figures the following limits of accuracy for individual cases may be claimed : (1) $75 \%$ of all cases will be predicted within 0.1 in. ; and (2) $95 \%$ of all cases will be predicted within 0.15 in. $(3.8 \mathrm{~mm}$.) of the calliper measurements. For groups of over 16 cases, however, accuracy to within 0.02 in. may be claimed for the mean reading.

It was observed during this investigation that, although the majority of biparietal estimations carried out during the last seven days of pregnancy were accurate to within 0.1 in., the calculated biparietals were always too large when cephalometry was performed earlier than two weeks before delivery. They were too large in every case, provided an allowance was made for growth of the biparietal diameter at a rate of 0.1 in. a week.

For example, if a biparietal diameter was estimated at 3.6 in. $(9.14 \mathrm{~cm}$.) at the 37 th week of pregnancy, $0.3 \mathrm{in}$.
(7.6 mm.) was added for growth (Scammon and Calkins, 1929) and the calliper measurement should have been 3.9 . in. $(9.9 \mathrm{~cm}$.). In fact, however, the calliper measurement was found to be 3.6 in., and this disparity was true of every case examined during the 36th to 39th weeks of pregnancy.

There were therefore two possibilities to be considered : either (a) our method of cephalometry was accurate during the last week of pregnancy, but inaccurate if performed earlier than two weeks before delivery, or $(b)$ the foetal biparietal diameter did not grow during the last four weeks of intrauterine life. The latter concept was supported by the fact that the biparietal diameters estimated during the last four weeks were the same as the observed measurements carried out after delivery. We tried, therefore, to obtain further evidence to support this premise.

A group of cases were sent for cephalometry at the clinically estimated 36th week of pregnancy, and cephalometry was repeated four weeks later. The case sheets of this group were marked so that if the patient came into labour before the expected date emergency cephalometry could be performed.

The following is an example of one of these cases.

A primigravida aged 27 was sent for pelvi-cephalometry on February 11, 1949, and the foetal biparietal diameter was calculated to be $3.55 \mathrm{in}$. $(9.02 \mathrm{~cm}$.) on that date (Fig. 1). Twentyone days later, on March 4, cephalometry was repeated, and the foetal biparietal diameter was calculated to be 3.6 in. (Fig. 2) -an increase of $0.05 \mathrm{in}$. (1.27 mm.), which is within the limits of experimental error. Eight days after this, on March 12, a female infant weighing $7 \mathrm{lb} .9 \mathrm{oz} .(3.43 \mathrm{~kg}$.) was delivered normally, and its biparietal diameter measured 3.55 in. There was thus no increase in the foetal biparietal diameter during the last 29 days of this pregnancy.

Fig. 3 shows the two previous films arranged so that the foetal skull shadows are superimposed, and it can be seen that they do accurately coincide. Fig. 4 shows the two maternal pelves superimposed, showing that the foetal head has made some descent during the 21 days between exposures.

In each of the 223 radiological estimations the amount of growth from the date of the examination until the date

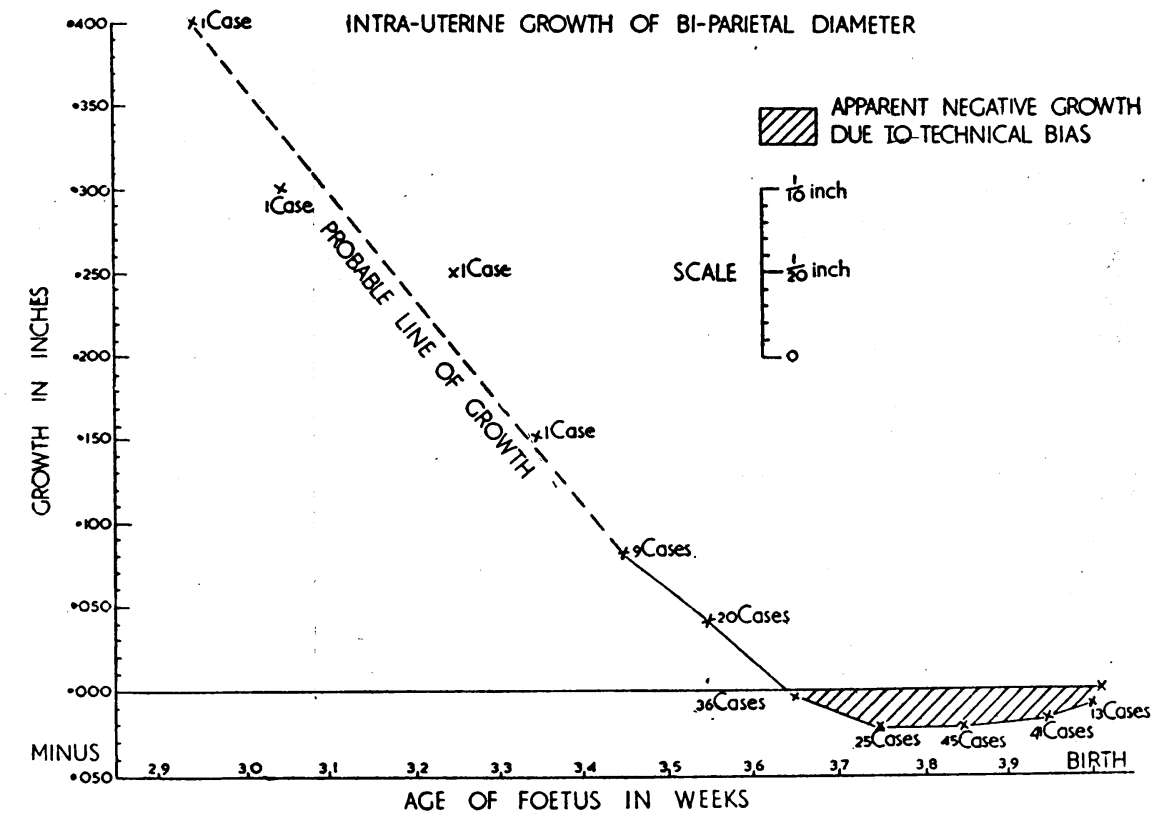

FIG. 5.-The total growth of the biparietal diameter of the foetal skull from the date of estimation until birth. The growth of the skull is estimated from the intrauterine radiological measurement and the actual calliper measurement three days after birth; the difference between these readings gives the growth in the intervening period. 
of delivery was calculated from the two readings available. The cases were then grouped according to the number of weeks that elapsed between examination and delivery, and an average of each group was calculated. These growth figures are given in Table III. The standard error of the means of these groups is \pm 0.02 in.

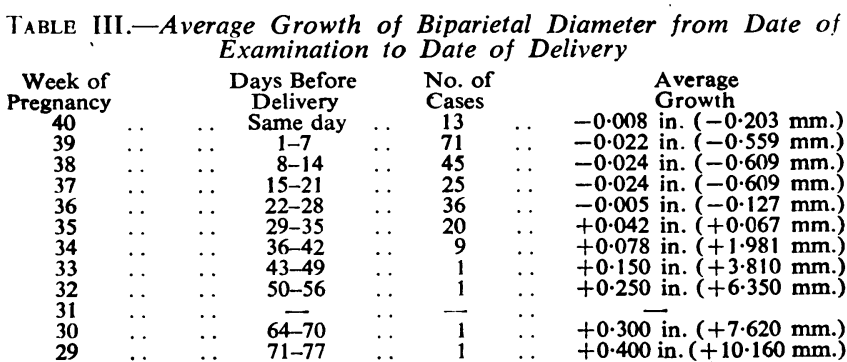

The notable features of this table are: (1) The radiological method overestimates the size of the head by approximately 0.02 in. Consequently there is an apparent slight negative growth in the later stages (see Fig. 5). (2) There is no sign of a growth curve between the 36th and 40th weeks of pregnancy. (3) The growth curve between the 30 th and 36 th weeks cannot yet be accurately assessed. owing to scanty data, but even at this stage the biparietal diameter appears to grow at a rate of less than 0.1 in. a week.

We have now collected 34 cases in which radiological cephalometry was performed twice, with an interval of 21 days or more between the examinations. In 13 cases both radiological examinations were performed during the last 28 days of pregnancy, and the apparent growth between the two radiological examinations was 0.02 in. This figure is within the limits of our experimental error and could not therefore be definitely attributed to growth. Further details of these 34 cases are given in Table IV.

TABLE IV.-Results of Two Radiological Examinations in Same Patient

\begin{tabular}{|c|c|c|c|}
\hline $\begin{array}{l}\text { Time from First } \\
\text { Radiological } \\
\text { Examination to } \\
\text { Date of Delivery }\end{array}$ & $\begin{array}{l}\text { No. of } \\
\text { Cases }\end{array}$ & $\begin{array}{l}\text { Average Time } \\
\text { between Two } \\
\text { Radiological } \\
\text { Examinations }\end{array}$ & $\begin{array}{c}\text { Average Growth } \\
\text { between Two } \\
\text { Radiological } \\
\text { Examinations }\end{array}$ \\
\hline $\begin{array}{ll}28 \text { days or less } & \ldots \\
29-35 \text { days } \ldots & \ldots \\
36 \text { days or more } & \ldots\end{array}$ & $\begin{array}{r}13 \\
13 \\
8\end{array}$ & $\begin{array}{l}24 \text { days } \\
26 " ” \\
30 ",\end{array}$ & $\begin{array}{l}0.02 \text { in. }(0.508 \mathrm{~mm} .) \\
0.04 \text { in. }(1.016 \mathrm{~mm} .) \\
0.12 \text { in. }(3.048 \mathrm{~mm} .)\end{array}$ \\
\hline
\end{tabular}

For reasons stated above we have estimated radiologically only the biparietal diagmeters, and have no observations to offer on the growth, or lack of growth, of the other diameters of the foetal skull during this period. In the absence of craniostenosis, however, it seems illogical to suppose that one diameter of the foetal skull should remain stationary while the others increase.

The investigation continues, and we are trying to estimate the foetal biparietal diameters at 32 weeks, again at 36 weeks, and then at term. Thereby we hope to observe the rate of growth between the 32nd and 36th weeks of pregnancy and to obtain further confirmation of the absence of growth between the 36th and 40th weeks.

\section{Summary}

Two hundred and twenty-three estimations of intrauterine foetal biparietal diameters, performed on 189 patients, are compared with calliper measurements obtained on the third day after birth.

Eighty-four cases were estimated radiologically within seven days of delivery.
In 34 cases radiological cephalometry was performed twice, with a minimum of 21 days between the examinations.

For individual cases the predicted measurement will be within 0.1 in. of the calliper measurement in $75 \%$ of cases, and within 0.15 in. in $95 \%$ of cases.

For groups of over 16 cases, accuracy of 0.02 in. may be claimed for the mean reading.

Radiological cephalometry overestimates the biparietal diameters by approximately 0.02 in.

There is no sign of a growth curve bietween the 36th and 40th weeks of pregnancy.

Grateful thanks are due to the staffs of the obstetrical and radiological departments of the Newcastle General Hospital; to Mr. F. Pearse, senior radiographer, who produced many of the radiographs of these cases; to Dr. Mary Buchanan and Dr. W. Ingham, who assisted Dr. Fawcett in her measurements ; to Dr. Whately Davidson, radiologist in charge, Newcastle General Hospital, Mr. Linton Snaith, obstetrician in charge, Newcastle General Hospital, and Dr. Blair Hartley, honorary radiologist to the Christie Hospital and Holt Radium Institute, Manchester, for their criticism and encouragement in this work.

\section{REFERENCES}

Moir, Chassar J. (1946). J. Obstet. Gynaec. Brit. Emp., 53, 487. Reece, L. N. (1935). Proc. R. Soc. Med., 28, 489.

Scammon, R. E., and Calkins, L. A. (1929). Growth in the Foetal Period, University of Minnesota Press, Minneapolis.

\section{THE SHORT OESOPHAGUS A REVIEW OF 31 CASES}

BY

J. BASIL RENNIE, M.D., M.R.C.P., F.R.F.P.S.G. FRANK T. LAND, M.B., Ch.B., F.R.F.P.S.G., D.L.O. AND

S. D. SCOTT PARK, M.B. Ch.B., D.M.R.E. (From the Gardiner Institute of Medicine, University of Glasgow, and the Ear, Nose, and Throat and Radiology Departments, Western Infirmary, Glasgow)

Although the association of gastric hernia with shortening of the oesophagus is no new conception, it is far from widely appreciated that it can produce a variety of symptoms simulating carcinoma of the oesophagus, peptic ulceration of stomach or duodenum, cholelithiasis, and even disease of the coronary arteries. In this communication, therefore, we propose to review the literature briefly, to discuss the incidence of the condition relative to other lesions of the lower third of the oesophagus, and to point out associations with pregnancy and post-operative oesophageal stricture which we believe have not been previously recognized.

Isolated references to patients described as having a short oesophagus were recorded years ago by physicians from findings at necropsy (Bright, 1836 ; Bund. 1918 ; Bailey, 1919). The radiologist Akerlund (1926) seems to have been the first to differentiate hernia of the stomach through the oesophageal hiatus into

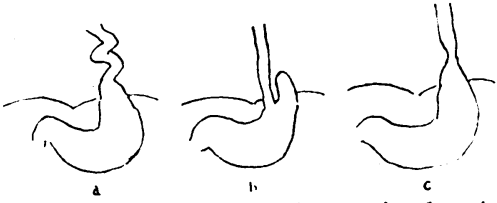

FIG. 1.-Varieties of gastric hernia hrough the oesophageal hiatus. $a$ Oeosophago-gastric; $b$, para-oesophageal; $c$, with short oesophagus. three types according to the $x$-ray appearances (Fig. 1). In the oesophago-gastric variety $(a)$ the oesophagus is redundant and tortuous, in the para-oesophageal $(b)$ the oesophagus enters the stomach below the diaphragm and the gastric hernia passes up beside if while in hiatal hernia with short oesophagus $(c)$ the gast -oesophageal junction is above the diaphragm but the oeso; agus is not redundant. 